\title{
An Empirical Study on the Influence of Industrial Openness on Employment Structure in Eastern China
}

\author{
Zhenbiao Yang ${ }^{1, a,{ }^{*}, \text { Guobin Lin }}{ }^{2, b}$
}

${ }^{1}$ School of Economics and Commerce, South China University of Technology, Guangzhou, Guangdong, China

${ }^{2}$ School of economics and Commerce, South China University of Technology, Guangzhou, Guangdong, China

a523822922@qq.com, b4419621@qq.com

Keywords: Eastern China; Industrial openness; Employment structure.

\begin{abstract}
The changes of internal and external economic situation in China make the economy and employment of eastern china face new challenges. This paper studies the influence of industrial openness on employment structure from three angles of trade, investment and production, using 2000-2014 panel data of the provinces, to observe the characteristics of employment structure from the two aspects of enterprise and industry structure. The results show that the structure of industrial employment enterprises in eastern China is mainly affected by the opening of production, while the trade structure is mainly affected by trade openness. This paper can provide reference for Chinese government to improve industrial upgrading and employment quality.
\end{abstract}

\section{中国东部工业对外开放对其就业结构影响的实证研究}

\author{
杨镇标 ${ }^{1, a,{ }^{*}}$ ，林国涁 $2, b$, \\ 1华南理工大学经济与贸易学院, 广州, 广东, 中国 \\ 2华南理工大学经济与贸易学院, 广州, 广东, 中国 \\ a523822922@qq.com, b4419621@qq.com
}

关键词: 中国东部；工业对外开放；就业结构

中文摘要. 中国内外部经济形势的变化，使东部的工业经济和工业就业面临新的挑战。本文 从工业的贸易、投资和生产等三个角度研究工业开放对其就业结构的影响，运用2000-2014年 全国各省的面板数据，从企业结构和行业结构两个方面观察就业结构的特征。结果显示：东 部工业就业企业结构主要受生产开放的影响, 而行业结构主要受贸易开放的影响。本文可为 中国政府有关产业升级和就业质量提升等政策制定提供参考。

\section{1. 引言}

中国是传统的劳动资源充裕性国家，低廉的劳动力和原材料成本是东部地区出口导向工 业在过去三十年得以快速发展的根基所在。作为最早开放的地区性主导产业, 中国东部工业 的产值规模和对外联系程度与其他区域及产业相比有着巨大的领先优势，工业化创造了大量 的就业岗位，为东部国民经济的发展以及产业内部转型升级发挥了不可磨灭的贡献。

然而，随着近年物价的轮番上涨、用工政策的完善和老龄化社会发展，东部地区工业在 劳动力成本比较优势上相对于我国中西部地区及其他发展中国家而言已经大为减弱。与此同 
时，东部地区工业经济的对外市场依赖程度却表现出逐年攀升的大趋势。2008次贷危机之后 全球经济持续低迷，外需长期疲软，劳动力成本的快速上升使得东部地区工业同质化产品的 整体国际竞争力出现不断下降, 通过加大机械和更为尖端的技术替代现有劳动力以压缩产品 成本的生产需求越来越成为东部地区工业企业赖以生存的手段, 在这样的情况下, 东部地区 工业劳动力需求必将面临着进一步的下降。

学界提出产业升级，提振内需和大力发展服务业等方案来抵消东部工业就业所面临的问 题。但是, 进入以技术广泛传播和行业生产结构升级加快为主要特征的后工业化时代, 随着 全球与国内产品市场需求一体化进度的加快, 东部地区工业对于超前产品的生产需求已经变 得越来越大。而东部工业目前的劳动力素质结构依然是为中低水平为主, 这并不能很好地适 应工业对外开放过程中消费者对于产品需求和技术更替提出的新要求。在工业对外经济市场 形势的快速变化环境下, 低效率行业企业的衰退和倒闭会带来相应的劳动力失业, 而高效率 的行业企业则出于提升行业地位的目的而不断提高劳动力的就业素质要求, 进而减少对低素 质劳动力的需求。劳动力市场中以高素质为核心为需求变化对东部工业当前劳动力的组成结 构提出了新的挑战, 过去为了迎合和依靠规模野蛮扩张而盲目地扩大劳动力雇佣的倾向已经 不具备可持续发展的内在动力。

总之, 当前东部工业就业面临不小的结构问题, 企业的用工需求与劳动力素质间的矛盾 加剧, 新的经济形势对现有的就业结构提出了挑战。

\section{2. 文献综述}

学术界很早就关注到工业开放对工业就业结构的影响。从发达国家的发展来看，由于其 大多具备良好的发展基础, 随着对外开放程度的提高, 其技术和资本要素禀赋得以在更宽阔 的范围进行扩散, 通过比较优势和要素禀赋的差异发展, 这些国家中相关产业的劳动生产率 普遍得到了提高, 并在很大程度上加快了高素质劳动力对低素质劳动力的就业替代。Slaughter （2001）检验了美国贸易自由化对产业劳动力就业结构的影响, 发现生产性劳动力就业在考 虑时间因素后与贸易开放的关系不显著, 而非生产性劳动力就业明显受到贸易开放的影响 ${ }^{[1]}$ 。 Burstein \& Vogel（2010）的研究认为, 对外开放能促进发达国家对高技术劳动力的需求比重 以及发展中国家对中低技能劳动力需求比重 ${ }^{[2]}$ 。随着加工贸易的发展以及产品同质化趋势的 不断扩大, 与 $\mathrm{H}-\mathrm{O}$ 等传统理论观点不同的是, Acharya（2015）[3]等学者发现了发展中国家贸 易自由化并不能提高其对低素质劳动力的需求比重。对此, 学术界开始提出产业内贸易理论、 新地理经济以及企业异质性等理论开展深入研究, 典型如 Yeaple (2005) 通过推导的企业异 质模型发现，在就业市场均衡状态下，参与国际经济的企业对劳动者技能的要求相对更高 ${ }^{[4]}$ 。 类似地, Molina \& Muendler（2009）基于技能偏向性技术进步模型对发展中国家样本开展的 实证分析发现, 企业生产效率与其开放程度呈正向相关, 企业生产效率的差异影响了其对于 劳动者素质的要求 ${ }^{[5]}$ 。

除了从贸易维度研究对外开放的就业结构影响外，也有不少国外学者从投资开放角度开 展了相关研究。Fajnzylber \& Femandes（2004）利用世界银行调查数据研究了对外贸易、FDI 等开放变量的就业影响效应, 发现巴西的投资对外开放有利于促进了高技能劳动力的就业比 重 ${ }^{[6]}$ 。

结合前文文献综述的研究角度，本文提出从贸易开放、投资开放和生产开放三个角度考 察工业对外开放对就业影响效应在工业的内部就业结构效应方面的影响, 并将针对其内部的 企业结构以及行业结构两层面开展对比研究。其中，东部地区工业就业的企业结构的概念定 义为国有及其控股企业年平均从业人数占工业全部企业年平均从业人数的比例, 而工业就业 的行业结构的概念定义为资本技术密集型行业年平均从业人数占工业全部行业年平均从业人 数的比例。由于学术界尚未形成具有统一方法的产业要素密集划分方法, 且工业生产要素存 在着部分的可替代性特征, 资源密集型产业的划分边界仍然比较模糊, 因此本文将食品加工 业、家具制造业、服装及其它纤维制品业等在内的16个工业二级细分行业作为传统意义上的 
劳动密集型行业, 而将其余行业作为资本技术密集型行业来开展工业两大部类就业的行业结 构分析。

\section{3. 模型、数据与变量}

\section{1 模型设定}

为多方面反映东部工业对外开放发展中一系列影响其就业结构的深层因素，本文拟从企 业所有制性质和工业行业生产的要素密集度两大角度研究工业的就业结构效应。在模型构建 上，本文通过对 Diewert（1974）提出的超对数成本函数进行分解，进而推导出工业开放就业 结构影响模型 ${ }^{[7]}$ 。该函数假设: 在产业就业市场存在准固定要素成本的条件下，劳动力的要 素投入在短期内将与其相匹配的资本投入保持固定比例。基于此, 可建立如下可分解成本方 程:

$$
\begin{aligned}
\ln C= & \sum_{k=1}^{K} \beta_{k} \ln G_{k}+\sum_{q=1}^{Q} \beta_{q} \ln W_{q}+\frac{1}{2}\left(\sum_{k=1}^{K} \sum_{\mathrm{k}^{\prime}=1}^{K} \beta_{\mathrm{kk}^{\prime}} \ln G_{k} \ln G_{k^{\prime}}+\sum_{q=1}^{Q} \sum_{q^{\prime}=1}^{Q} \beta_{q q^{\prime}} \ln W_{q} \ln \mathrm{W}_{q^{\prime}}+\sum_{r=1}^{R} \sum_{r^{\prime}=1}^{R} \beta_{r r^{\prime}} \ln \mathrm{O}_{r^{\prime}} \ln \mathrm{O}_{r^{\prime}}\right) \\
& +\frac{1}{2}\left(\sum_{k=1}^{K} \sum_{\mathrm{q}=1}^{Q} \beta_{k q} \ln G_{k} \ln W_{q}+\sum_{r=1}^{R} \sum_{q=1}^{Q} \beta_{r q} \ln \mathrm{O}_{r} \ln \mathrm{W}_{q}+\sum_{k=1}^{K} \sum_{r=1}^{R} \beta_{\mathrm{n} \mathrm{r}} \ln G_{k} \ln \mathrm{O}_{r}\right)+\beta_{0} \sum_{r=1}^{R} \beta_{r} \ln \mathrm{O}_{r}
\end{aligned}
$$

式 (1) 中, $W_{q}$ 为不同结构类型劳动力的实际工资, $G_{k}$ 为准固定要素（资本）的投入参 数方程, 其与产业产出之间存在着固定的线性关系, 即 $G_{k}=\xi k y 。 O_{r}$ 为引起产业成本函数变 动的对外开放因素和外生技术进步因素。为了获取不同劳动力的成本结构份额, 将式 (1) 求 解对 $\ln W_{q}$ 的偏导数并整理得:

$$
\frac{\partial \ln C}{\partial \ln W_{q}}=\beta_{q}+\sum_{q=1}^{Q} \beta_{q} \ln W_{q}+\sum_{k=1}^{K} \beta_{k q} \ln G_{k}+\sum_{r=1}^{R} \beta_{r q} \ln \mathrm{O}_{r}
$$

进一步地, 由 $\frac{\partial \ln C}{\partial \ln W_{q}}=\frac{\partial C}{\partial W_{q}} \cdot \frac{W_{q}}{C}$, 其中根据谢泼德引理可知, $\frac{\partial C}{\partial W_{q}}$ 为第 $\mathrm{q}$ 类劳动力的需 求, 因此 $\frac{\partial \ln C}{\partial \ln W_{q}}=\frac{\partial C}{\partial W_{q}} \cdot \frac{W_{q}}{C}=\frac{L_{q} \cdot W_{q}}{C}$ 可理解为产业内部的劳动力结构 $S_{q}$ 。

此外，参照Bermen et al（1994）和 Hijzen et al（2005）的做法, 将对式（2）引入具体 的产业对外开放以及外生技术进步变量, 并将工资以及产业产出等变量提取并组合为比例形 式 ${ }^{[8-9]}$ 。即有:

$$
S_{q}=\beta_{q}+\sum_{q, q^{\prime}=1}^{Q} \beta_{q q^{\prime}} \ln \frac{\mathrm{W}_{q}}{W_{q^{\prime}}}+\beta_{k y q} \ln \left(\frac{k}{y}\right)_{i t}+\beta_{q \text { tech }} t e c h_{i t}+\beta_{q T O} T O_{i t}+\beta_{q P O} P O_{i t}+\beta_{q I O} I O_{i t}
$$

式 (3) 中, $\mathrm{W}_{q} / W_{q^{\prime}}$ 为劳动者间的工资比率, 需要指出的是, 虽然目前我国并没有对工 业细分行业的工资数据进行统计，但根据 Bermen et al（1994）的研究观点：假如产业内不同 类型的劳动力能够在较大程度上自由流动, 那么该工资比率将趋于稳定 ${ }^{[8]}$ 。基于此, 劳动者 间的工业比率可以通过设立常数项的方式进行替代分析。

最后, 考虑时间趋势对劳动力就业结构的影响, 对式 (3) 由水平方程转换为动态方程, 得出本文估计东部工业对外开放就业结构影响的实证模型：

$$
\Delta S_{i q}=\beta_{q}+\beta_{k y q} \ln \Delta\left(\frac{k}{y}\right)_{i t}+\beta_{q t e c h} \Delta t e c h_{i t}+\beta_{q T O} \Delta T O_{i t}+\beta_{q P O} \Delta P O_{i t}+\beta_{q I 0} \Delta I O_{i t}+\tau_{t}+\Delta \mathrm{c}
$$

\section{2 数据说明}

笔者运用 2000-2014 年中国东部地区工业对外经济比较发达的省市的面板数据作为研究 
对象。另外，本文使用的行业数据是中国国民经济行业分类标准（GB/T4754-2011）中的 39 个主要细分工业行业, 并按照前文提及的分类方法, 将各地区相应的行业按照要素密集程度 划分为劳动密集型和资本技术密集型行业。最后，本文数据来源于全国、各省市统计年鉴。

\section{3 变量说明}

就业总量 L: 各省市工业全部年平均从业人数。

实际工资 $\mathrm{W}$ ：各省市工业平均工资，具体求法是将各省市工业人员的工资总额除以该行 业年平均从业人数而得, 并利用居民物价指数进行平减。

企业结构 $S_{1}$ : 将国有及其控股企业年平均从业人数占工业全部企业年平均从业人数的比 例作为东部地区工业就业的企业结构指标。

行业结构 $S_{2}$ : 将资本技术密集型行业占工业的全部年平均工业人数的比例作为东部地区 工业行业就业的行业结构指标。

资本存量 $\mathrm{K}$ : 采用永续盘存法对工业资本存量做大致的估算, 公式为 $K_{i t}=K_{i, t-1}(1-\xi)+I_{i t}$ 。 其中, $\xi$ 为资本折旧率, 设定为 $10.5 \%, I_{i t}$ 是由固定资产投资价格指数折算后的工业固定资产 投资总额。另外, 将基期 2000 年的资本存量设为 $K_{2000}=I_{2000} /(g+\xi), g$ 是工业固定资产总额 的年平均增长率。

工业产出 Y：使用经工业品出厂价格指数折算后的各地区工业增加值。

技术进步率 tech: 各省市工业 R\&D 的年平均全时从业人数占工业全部从业人数的比值进 行衡量。

贸易开放度 TO: 以主要工业品进出口总额与工业产业增加值间比率来进行衡量。

生产开放度 PO：运用东部地区三资工业企业生产总值与工业生产总值的比值。

投资开放度 IO：外商直接投资年流量占工业增加值比重。

通过对各模型所有变量进行处理和统计描述分析, 可得到表 1:

表1 变量的描述性统计

\begin{tabular}{|c|c|c|c|c|c|c|c|c|c|c|}
\hline 变量 & $\begin{array}{c}\text { 就业总 } \\
\text { 量 } \mathrm{L}\end{array}$ & $\begin{array}{c}\text { 平均工 } \\
\text { 资 } \mathrm{W}\end{array}$ & $\begin{array}{c}\text { 企业结 } \\
\text { 构 } \mathrm{S}_{1}\end{array}$ & $\begin{array}{c}\text { 行业结 } \\
\text { 构 } \mathrm{S}_{2}\end{array}$ & $\begin{array}{c}\text { 资本存 } \\
\text { 量 } \mathrm{K}\end{array}$ & $\begin{array}{c}\text { 资本产 } \\
\text { 出比 } \\
\mathrm{K} / \mathrm{Y}\end{array}$ & $\begin{array}{c}\text { 技术进 } \\
\text { 步 tech }\end{array}$ & $\begin{array}{c}\text { 贸易开 } \\
\text { 放度 } \\
\text { TO }\end{array}$ & $\begin{array}{c}\text { 生产开 } \\
\text { 放度 } \\
\mathrm{PO}\end{array}$ & $\begin{array}{c}\text { 投资开 } \\
\text { 放度 } \mathrm{IO}\end{array}$ \\
\hline 均值 & 430.7 & 258039 & 0.18 & 0.359 & 701347 & 1.59 & 0.02 & 0.86 & 0.32 & 0.06 \\
\hline 标准差 & 377.76 & 14789 & 0.09 & 0.04 & 130564 & 0.77 & 0.01 & 0.4 & 0.19 & 0.03 \\
\hline
\end{tabular}

\section{4. 实证结果及分析}

本文使用差分广义矩估计法（DGMM）和系统广义矩估计法（SGMM）对样本进行理论 模型的估计。利用 Stata12 对面板数据进行就业企业结构模型以及就业行业结构模型的估计可 以得到表 2 。

\section{（1）工业对外开放对其就业企业结构的影响分析}

通过表 2 显示的企业效益可以得出东部对外开放对国有性质企业就业的比重结构影响。 从东部工业整体样本的回归结果看, 生产的对外开放对于降低国有企业人数比重具有较为明 显的作用, 其回归系数达到了- 0.116 。工业贸易开放也表现出一定的影响作用, 但其影响作用 较为有限, 回归系数只有 -0.025 。此外, 由于工业投资开放指标的 $\mathrm{T}$ 统计量不显著且系数只 有 0.003 , 故无法就其对就业企业结构的影响展开说明。总结以上结果分析可知, 在所有对外 开放因素中, 主要影响东部整体工业就业企业结构的是生产维度的对外开放。在生产开放扩 大的背景下, 本土的外国企业通过生产效率以及产品生产成本领先等方面的比较优势加快了 国有工业企业为了谋求生存发展而推动的企业体制改革, 并通过发挥间接的知识技术溢出效 
应及示范效应，明显地推动了多种所有制企业就业比重的提升。

总的来说，东部工业的生产开放的扩大能更好地促进国有企业的改制以及本土外国企业 溢出效应的发挥，从而有利于多种工业企业所有制格局的形成，但贸易和投资开放并没有显 著的影响效用。其中，东部各地区贸易和生产开放水平的提高对非国有企业就业比重的提高 都具有积极的促进作用。

\section{（2）工业对外开放对其就业行业结构的影响分析}

通过表 2 显示的行业效应可以得出分析工业开放的就业行业结构效应，即东部整体的工 业对外开放指标系数中只有贸易开放系数为正，而其余两个指标系数较小且为负。该结果的 出现更多地验证了前文提出的对外开放就业行业结构效应：即东部地区贸易开放有利于促进 工业内部行业分工的深化，为非劳动力要素密集行业就业比重的扩大创造了条件。同时，东 部工业外企的生产和外资的行业流入倾向依然以劳动密集型行业为主, 投资开放和生产开放 并不利于资本技术密集型行业相对就业比重的扩大。也就是说，只有贸易开放有利于促进东 部资本技术密集型行业的就业比重，而其余两开放指标起到较弱的反向作用。

表2 东部地区工业对外开放对其就业企业结构、行业结构影响的实证结果

\begin{tabular}{|c|c|c|c|c|}
\hline \multirow{2}{*}{ 变量 } & \multicolumn{2}{|c|}{ 企业结构 } & \multicolumn{2}{|c|}{ 行业结构 } \\
\hline & DGMM & SGMM & DGMM & SGMM \\
\hline \multirow{2}{*}{$\mathrm{S}_{1, \mathrm{t}-1}$} & $0.297^{\star * *}$ & $0.585^{\star \star *}$ & $0.714^{* \star \star}$ & $0.766^{\star \star *}$ \\
\hline & $(2.76)$ & $(5.72)$ & $(11.56)$ & $(18.53)$ \\
\hline \multirow{2}{*}{$S_{1, t-2}$} & 0.105 & $0.101^{* *}$ & $0.130^{\star * *}$ & $0.117^{* * *}$ \\
\hline & $(1.56)$ & $(2.33)$ & $(2.88)$ & $(3.03)$ \\
\hline \multirow{2}{*}{$\operatorname{Ln}(\mathrm{K} / \mathrm{Y})$} & 0.031 & 0.016 & 0.008 & 0.05 \\
\hline & $(0.54)$ & $(1.4)$ & $(0.97)$ & $(0.63)$ \\
\hline \multirow{2}{*}{ tech } & $-5.138^{*}$ & $-3.49^{\star *}$ & 1.75 & $2.564^{* * *}$ \\
\hline & $(-1.89)$ & $(-1.95)$ & $(0.06)$ & $(2.73)$ \\
\hline \multirow{2}{*}{ LnTO } & -0.018 & $-0.025^{*}$ & $0.139^{\star *}$ & $0.216^{\star \star \star}$ \\
\hline & $(-1.24)$ & $(-1.68)$ & $(1.8)$ & $(7.65)$ \\
\hline \multirow{2}{*}{ LnPO } & $-0.242^{*}$ & $-0.116^{* * *}$ & -0.01 & $-0.015^{\star}$ \\
\hline & $(-1.76)$ & $(-3.35)$ & $(-1.28)$ & $(-1.81)$ \\
\hline \multirow{2}{*}{ LnIO } & 0.005 & 0.003 & 0.021 & $-0.037^{\star}$ \\
\hline & $(0.33)$ & $(0.65)$ & $(0.48)$ & $(-1.90)$ \\
\hline \multirow{2}{*}{ Constant } & $-1.567^{* * *}$ & $-0.437^{\star}$ & $0.152^{\star \star *}$ & $0.109^{* \star *}$ \\
\hline & $(-3.03)$ & $(-1.72)$ & $(7.57)$ & $(6.59)$ \\
\hline Wald & $443.12^{* \star *}$ & $898.23^{* * *}$ & $1750.4^{* \star *}$ & $3143.9^{\star \star \star}$ \\
\hline $\operatorname{AR}(2)-p$ & 0.212 & 0.187 & 0.124 & 0.212 \\
\hline Sargan-p & 0.08 & 0.315 & 0.075 & 0.139 \\
\hline
\end{tabular}

注: 表中***、**、*分别表示参数在 $1 \%, 5 \%$ 和 $10 \%$ 水平上显著, 括号内为 $\mathrm{T}$ 统计量, 限于篇幅, 不展示时间 虚拟变量结果

\section{5. 研究结论}

本文通过总结归纳前人关于对外开放就业影响的相关研究成果, 立足于对东部地区工业 就业的现实考察, 在评估东部工业对外开放发展状况的基础上, 从就业结构方面实证研究及 比较对外开放对东部就业的具体影响。据此, 总结本文的主要结论如下:

第一，就业市场变化是东部地区工业结构转型及其对外经济发展状况的内在反映。受当 前国际市场需求变化的关联影响，东部地区工业就业总体表现出增速持续放缓的过渡趋势。 
随着国有企业改制的深入以及产业结构的不断升级，东部地区工业就业在形成以多种所有制 企业及不同要素密集生产行业共同发展的基本格局的同时，其劳动力流向依然是以劳动密集 型生产行业就业为主。

第二，东部各地区工业贸易及生产开放推动了非国有工业企业就业比重的提升。随着国 际分工参与度的提高以及生产结构的转型, 东部地区工业就业的行业结构虽然已经从过去以 劳动密集型为主逐步向多种要素平衡发展的趋势迈进, 但在生产模式上对工业劳动力的相对 要素利用程度仍然偏高, 产业就业结构具有较大的优化空间; 受企业制度的改革以及工业生 产开放的影响，东部国有性质工业企业就业占比呈现不断下降的趋势，并形成了多种所有制 企业就业共同发展的格局。

\section{References}

[1] Slaughter, Matthew J. "International trade and labor-demand elasticities." Journal of International Economics 54.1 (2001): 27-56.

[2] Burstein, Ariel, and Jonathan Vogel. Globalization, technology, and the skill premium: A quantitative analysis. No. w16459. National Bureau of Economic Research, 2010.

[3] Acharya, Ram C. "Impact of Trade on Canada's Employment, Skill and Wage Structure." The World Economy (2015).

[4] Yeaple, Stephen Ross. "A simple model of firm heterogeneity, international trade, and wages." Journal of international Economics 65.1 (2005): 1-20.

[5] Molina, Danielken, and Marc-Andreas Muendler. Preparing to export. No. w18962. National Bureau of Economic Research, 2013.

[6] Fajnzylber, Pablo, and Ana Margarida Fernandes. International economic activities and the demand for skilled labor: evidence from Brazil and China. Vol. 3426. World Bank Publications, 2004.

[7] Diewert, W. Erwin. "Functional forms for revenue and factor requirements functions." International Economic Review (1974): 119-130.

[8] Berman, Eli, John Bound, and Stephen Machin. Implications of skill-biased technological change: international evidence. No. w6166. National Bureau of Economic Research, 1997.

[9] Hijzen, Alexander, Holger Görg, and Robert C. Hine. "International outsourcing and the skill structure of labour demand in the United Kingdom."The Economic Journal 115.506 (2005): 860-878. 